\title{
Plasminogen Activator Inhibitor Is Associated with the Extracellular Matrix of Cultured Bovine Smooth Muscle Cells
}

\author{
Beatrice S. Knudsen, Peter C. Harpel, and Ralph L. Nachman \\ Division of Hematology-Oncology and the Specialized Center of Research in Thrombosis, \\ Cornell University Medical College, New York 10021
}

\begin{abstract}
The extracellular matrix secreted by cultured bovine smooth muscle cells (BSMC) contains an endothelial type plasminogen activator (PA) inhibitor. When PA is incubated with the matrix, a high molecular weight complex containing a truncated PA inhibitor is released into the supernatant. The inhibitor also dissociates from the matrix by treatment with glycine, pH 2.7, in its intact, functionally active, $45-\mathrm{kD}$ form, whereas treatment of the matrix with thrombin results in the release of a cleaved, inactive, $41 \mathrm{kD}$ PA inhibitor. Bowes melanoma cells but not smooth muscle cells cultured on BSMC matrices decrease available matrix associated PA inhibitor. PA inhibitor incorporated into the extracellular matrix may serve an important role in the regulation of plasminogen activator mediated matrix degradation.
\end{abstract}

\section{Introduction}

The serine proteases tissue plasminogen activator (t-PA) ${ }^{1}(1)$ and urinary plasminogen activator (u-PA) (2) convert the zymogen plasminogen into the serine protease plasmin and thereby have been implied in various physiological and pathological processes including fibrinolysis (3), cellular migration (4), neuronal outgrowth (5), ovulation (6), activation of latent collagenase (7), and tumor metastasis (8). Whereas plasminogen activators (PAs) possess greatly restricted substrate specificity, plasmin cleaves a wide range of proteins. A complex regulatory system exists to ensure the localized and controlled generation of plasmin that involves the regulation of PA production and plasminogen activation. A variety of serine protease inhibitors limit t-PA, u-PA and plasmin activity (9). Most cells synthesize both PA and their inhibitors and thereby determine the level of PA activity in the cellular microenvir-

Parts of this work have appeared in abstract form. 1986. J. Cell Biol. 103:253a.

Address reprint requests to Dr. Nachman, Division of Hematology-Oncology, C-606, Cornell University Medical College, 1300 York Avenue, New York, NY 10021.

Received for publication 11 December 1986 and in revised form 27 May 1987.

1. Abbreviations used in this paper: BSMC, bovine smooth muscle cells; PA, plasminogen activator; PAI-1, endothelial plasminogen activator inhibitor; PAI-2, placental plasminogen activator inhibitor; PPACK; D-phenyl- $d$-alanyl-l-propyl-arginine; RFU, relative fluorescent units; t-PA, tissue-PA; u-PA, urokinase.

J. Clin. Invest.

(c) The American Society for Clinical Investigation, Inc.

$0021-9738 / 87 / 10 / 1082 / 08 \quad \$ 2.00$

Volume 80, October 1987, 1082-1089 onment. This equilibrium is shifted toward an excess production of inhibitors by a number of cellular stimuli including thrombin (10), endotoxin (11), lymphokines (12-14), and glucocorticoids $(15,16)$. Four distinct PA inhibitors, an endothelial PA inhibitor (PAI-1) (17-20), a placental PA inhibitor (PAI-2) (21), protease nexin (22), and a recently described urinary inhibitor (23) possess different substrate specificities, kinetic properties, and tissue distribution. PAI-1 and PAI-2 exhibit great specificity for t-PA and u-PA $(24,25)$. Whereas PAI- 1 is acid stable and inactivates t-PA and u-PA with similar efficiency (26), PAI-2 reacts more rapidly with u-PA and is acid sensitive (27). Protease nexin (28) and the urinary inhibitor in the presence of heparin react rapidly with u-PA and thrombin but much slower with t-PA.

The extracellular matrix is composed of a complex array of collagens, glycoproteins, and proteoglycans (29). This tight network of adhesive proteins functions as a barrier to cellular migration. Activated nonmalignant cells as well as tumor cells secrete enzymes that degrade matrix constituents and facilitate cellular movement (30). The extracellular matrix contains inhibitors of collagenases and stromolysin (31) that may play a role in preventing matrix destruction by invasive cells. In addition plasmin and u-PA affect matrix glycoproteins $(32,33)$. We have recently shown that plasminogen binds to the surface of the extracellular matrix where its activation by t-PA is enhanced as compared with the fluid phase. In addition, the newly generated matrix-associated plasmin is protected from its fast acting inhibitor $\alpha_{2}$-plasmin inhibitor (34). To effectively reduce plasmin-mediated matrix destruction, plasminogen activation rather than plasmin activity must be inhibited. We now present evidence that vascular extracellular matrix produced by cells in tissue culture contains a PA inhibitor. The localization and properties of this inhibitor suggest that it may play a regulatory role in the penetration of cells through the vessel wall.

\section{Methods}

Materials. $\left[{ }^{35}\right.$ S]Methionine and ${ }^{125} \mathrm{I}-\mathrm{Na}$ were purchased from New England Nuclear (Boston, MA), D-phenyl- $d$-alanyl-l-prolyl-l-arginine chloromethylketone (PPACK) from Calbiochem-Behring, La Jolla, CA, bovine serum albumin (BSA) from Miles Laboratories (Elkhart, IN), Litex agarose from Accurate Chemical \& Scientific Corp. (Westbury, NY), tissue culture plasticware from Nunc (Roskilde, Denmark), cell culture media from Mallinckrodt Bioproducts (St. Louis, MO) and Gibco Laboratories (Grand Island, NY), immunobeads (goat-anti rabbit coupled to beads) from Bio-Rad Laboratories (Richmond, CA) and Protein-A Sepharose from Pharmacia Fine Chemicals (Piscataway, NJ). The fluorogenic u-PA substrate, D-gly-gly-arg-7-amino-4-trifluoromethyl coumarin was obtained from Enzyme Systems Products (Livermore, CA). Para-nitrophenyl-p'-guanidino benzoate ( $p$-NPGB) was obtained from Vega Fox Biochemicals (Tucson, AZ).

Purified proteins. Plasminogen was prepared by affinity chromatography on lysine agarose as described (34). Recombinant t-PA was 
generously provided by Genentech, Inc. (San Francisco, CA); human high molecular weight two-chain urokinase (Winkinase) by the Sterling Winthrop Research Institute (New York) and bovine thrombin $(4,300 \mathrm{U} / \mathrm{mg}$ ) by Dr. John W. Fenton II (New York State Department of Health, Albany, NY). The urokinase was further purified by adsorption with Cibachrom-blue (Pharmacia Fine Chemicals) to remove the albumin and migrated as major bands between 30 and $35 \mathrm{kD}$ on reduced SDS-PAGE.

Antisera. Endothelial type plasminogen activator inhibitor antiserum was kindly provided by Dr. David Loskutoff (Scripps Research Foundation, La Jolla, CA) (35). Rabbit antiserum to u-PA was obtained from Alpha Therapeutic Corp., (Los Angeles, CA) rabbit antiserum to fibronectin was kindly provided by Dr. D. Falcone (Cornell University Medical College, New York). Fluoresceinated goat-anti rabbit (g $\alpha$ r-FITC) and goat immunoglobulin were purchased from Cappel Laboratories (Cochranville, PA).

Cell culture. Bovine smooth muscle cells, a generous gift from Dr. D. Hajjar (Cornell University Medical College) or Bowes human melanoma cells kindly supplied by Dr. D. Rifkin (New York University School of Medicine) were grown in minimal essential medium (MA Bioproducts, Walkersville, MD), $10 \%$ fetal calf serum, $10 \mathrm{mM}$ Hepes, pH 7.2, $2 \mathrm{mM}$ L-glutamine, $100 \mathrm{U} / \mathrm{ml}$ penicillin, $100 \mu \mathrm{g} / \mathrm{ml} \mathrm{strepto-}$ mycin (all Gibco) and maintained in T75 flasks or 24-well plates at $37^{\circ} \mathrm{C}$ in a humidified $95 \%$ air-5\% $\mathrm{CO}_{2}$ atmosphere until passage 15.

Preparation of extracellular matrices, acid extraction, thrombin treatment and exposure of matrices to cells. BSMC matrices were prepared according to the method of Gospodarowicz from confluent cell layers (36). Cells were first removed with $0.5 \%$ Triton in phosphatebuffered saline ( $\mathrm{pH} 7.4$ ) followed by a 10-min incubation with $25 \mathrm{mM}$ $\mathrm{NH}_{4} \mathrm{OH}$ to remove cytoskeletal elements. No cells remained on the plates as detected by light microscopy. After three washes in TrisTween buffer ( $20 \mathrm{mM}$ Tris- $\mathrm{HCl} \mathrm{pH} 7.4,150 \mathrm{mM} \mathrm{NaCl}, 0.05 \%$ Tween-20) matrices were incubated with $20 \mathrm{mM}$ glycine-HCl pH 2.7, the supernatants removed after $1 \mathrm{~h}$ and immediately neutralized with 1 $\mathrm{M} \mathrm{NaOH}$. Alternatively matrices were incubated with thrombin (10 U, $2.17 \mu \mathrm{g})$. After an hour incubation, the thrombin was inhibited by $10^{-6}$ M PPACK. To study the effects of cells on BSMC matrices, cells were trypsinized and the trypsin was inhibited with $10 \%$ fetal calf serum. After intensive washing in serum-free medium $3 \times 10^{5}$ cells per well were plated on the BSMC matrix. After a 4-h culture in serum-free medium, adherent cells were removed by a 5-min incubation with 25 $\mathrm{mM} \mathrm{NH}_{4} \mathrm{OH}$, the matrices were washed three times with Tris-Tween buffer and extracted with acid for $1 \mathrm{~h}$.

Production of labeled matrices. BSMC were grown to confluency in 24 well plates. The cells were incubated for $1 \mathrm{~h}$ with methionine free minimal essential medium containing $2 \%$ fetal calf serum, $25 \mathrm{mM}$ Hepes pH 7.2, 2 mM L-glutamine, penicillin, and streptomycin and labeled with $10 \mu \mathrm{Ci}\left[{ }^{35} \mathrm{~S}\right.$ ]methionine/ml for 8-12 h. Matrices were prepared as described and contained $6,000-8,000 \mathrm{cpm} /$ well. Matrices were solubilized in sample buffer $(0.625 \mathrm{M}$ Tris $/ \mathrm{HCl}, \mathrm{pH} 6.8,0.1 \%$ sodium dodecyl sulfate [SDS], $25 \%$ glycerol, bromphenol blue, 100 $\mathrm{mM}$ dithiothreitol) and analyzed by SDS-polyacrylamide gel electrophoresis (PAGE) and autoradiography.

Protein iodination. U-PA was labeled with ${ }^{125}$ I by the modified chloramine $T$ method as previously described (37) in the presence of benzamidine and the benzamidine subsequently removed by chromatography on a PD10 column (Pharmacia Fine Chemicals). Labeled u-PA contained $50-100 \times 10^{3} \mathrm{cpm} /$ Plough unit. Active site titrated ${ }^{125} \mathrm{I}-\alpha$-thrombin was kindly provided by Dr. Mark Brower (Cornell University Medical College).

Complex formation between $P A$ and matrix proteins. u-PA $(100 \mu \mathrm{l})$ was added either to BSMC matrices in 24-well plates directly or added to acid extracted matrix proteins. After a 30-min incubation, samples containing u-PA-protein complexes were either analyzed by SDSPAGE or used to quantify remaining u-PA activity after addition of the fluorometric u-PA substrate.

Quantitative fluorometric u-PA assay. u-PA enzymatic activity was determined upon addition of the specific fluorometric u-PA substrate
( $5 \mu \mathrm{M}$ final concentration in $300 \mu \mathrm{l}$ ), D-Gly-Gly-Arg-7-amino-4-trifluoromethyl coumarin. Substrate hydrolysis was measured in a spectrofluorometer (650-10S; Perkin-Elmer Corp., Norwalk, CT) at an excitation of $400 \mathrm{~nm}$ and an emission of $505 \mathrm{~nm}$ (slit width $=2 \mathrm{~nm}$ ) and was proportional to the amount of functionally active u-PA. u-PA activity was then obtained by plotting relative fluorescent units (RFU) versus time and the slope of each straight line used to quantify the amount of u-PA activity. The percentage of remaining u-PA activity after incubation with matrix proteins was expressed as the ratio of each slope to the slope obtained with an equal amount free u-PA. The rate constant of complex formation was calculated using the equation $k$ $=1 / t\left[E_{\mathrm{t}}^{-1}-E_{0}^{-1}\right]$ where $E_{\mathrm{t}}$ and $E_{0}(1.33 \mathrm{nM})$ represent the free u-PA (relative molecular weight $=53,000$ ) concentrations at time 0 and 4 $\min (38)$.

SDS-PAGE. 9\% Polyacrylamide gels were used, all samples analyzed under reduced conditions (sample buffer: $2 \%$ SDS and $5 \mathrm{mM}$ $\beta$-mercaptoethanol) except for zymography. To visualize ${ }^{35} \mathrm{~S}$-labeled protein gels were fluorographed before autoradiography. Prestained molecular weight markers (Bethesda Research Laboratories, Gaithersburg, MD) were used for molecular weight determination on all gels.

Immunoprecipitation. $10 \mu \mathrm{l} \alpha \mathrm{PAI}$ immune or preimmune serum was adsorbed with gor beads and the immobilized Ig was incubated with proteins released from ${ }^{35} \mathrm{~S}$-labeled matrices by acid or thrombin for $3-4 \mathrm{~h}$ at $22^{\circ} \mathrm{C}$ in the presence of $0.1 \%$ Tween 20 . The beads were washed six times at $4^{\circ} \mathrm{C}$ (washing buffer: $20 \mathrm{mM}$ Tris- $\mathrm{HCl}, \mathrm{pH} 8.3,0.3$ $\mathrm{M} \mathrm{NaCl}, 0.1 \% \mathrm{NP}-40,0.1 \% \mathrm{SDS}$ ) and once with Tris-buffered saline before solubilization in gel sample buffer. For functional studies $\alpha$ PAI immune or preimmune serum was adsorbed with protein $A$ beads and incubated with acid extracted proteins in the presence of $0.1 \%$ Tween 20 and $0.1 \%$ acid-treated BSA for $2 \mathrm{~h}$ at $22^{\circ} \mathrm{C}$; (BSA was treated with acid, $\mathrm{pH} 2.5$, neutralized, stored in the presence of phenylmethylsulfonylfluoride, and extensively dialyzed before use). $0.1 \mathrm{U}$ u-PA was then added for $1 \mathrm{~h}$ and the u-PA activity quantified by fluorometric measurements. To investigate the inhibitor in u-PA-PA inhibitor complexes $\left[{ }^{35}\right.$ S $]$ methionine-labeled u-PA-PA inhibitor complexes were isolated with a u-PA antiserum $(10 \mu \mathrm{l})$ coupled to protein A beads and incubated for $16 \mathrm{~h}$ with $1 \mathrm{M}$ Tris, $\mathrm{pH} 11$. The beads were removed by centrifugation and supernatants were directly analyzed by SDS-PAGE and autoradiography.

Reverse zymography. Reverse zymography was carried out using the procedure for reverse fibrin autography (19) but casein was substituted for fibrinogen and thrombin. Briefly, SDS-PAGE gel pieces were first soaked in $2.5 \%$ Triton and $\mathrm{H}_{2} \mathrm{O}$ for 30 min each and then layed onto casein indicator gels (1.25\% agarose, $2 \%$ Carnation dry milk; Carnation Co., Los Angeles, CA; $0.2 \mathrm{U} / \mathrm{ml} \mathrm{u}-\mathrm{PA}$ and $30 \mu \mathrm{g} / \mathrm{ml}$ plasminogen). The gels were developed for $4.5 \mathrm{~h}$ at $37^{\circ} \mathrm{C}$ in a humidified chamber and stained with amido black.

\section{Results}

Complex formation between an extracellular matrix protein and plasminogen activators. Bovine smooth muscle cells synthesize an extracellular matrix that remains tightly adherent to the culture plate after removal of cells by treatment with $0.5 \%$ Triton X-100 and $25 \mathrm{mM} \mathrm{NH}_{4} \mathrm{OH}$. When such matrices were incubated with ${ }^{125} \mathrm{I} \mathrm{u}-\mathrm{PA}$ in Tris-Tween buffer, $\mathrm{pH} 7.4$, a specific complex formed between u-PA and a matrix component that dissociated from the matrix and appeared in the supernatant (Fig. 1 $A$ ). Whereas reduced two-chain u-PA migrated with an apparent molecular weight of 30-35 kD (Fig. $1 A$, lane 1), SDS-PAGE autoradiographic analysis of reduced matrix supernatants showed a second band at $78 \mathrm{kD}$ that contained ${ }^{125} \mathrm{I} \mathrm{u}-\mathrm{PA}$. The association between the ${ }^{125} \mathrm{I} \mathrm{u}-\mathrm{PA}$ and the unlabeled matrix protein was stable to boiling in SDS under reducing conditions, a finding consistent with covalent bond formation between u-PA and the matrix component. To show that the matrix-associated u-PA binding protein was synthe- 
A

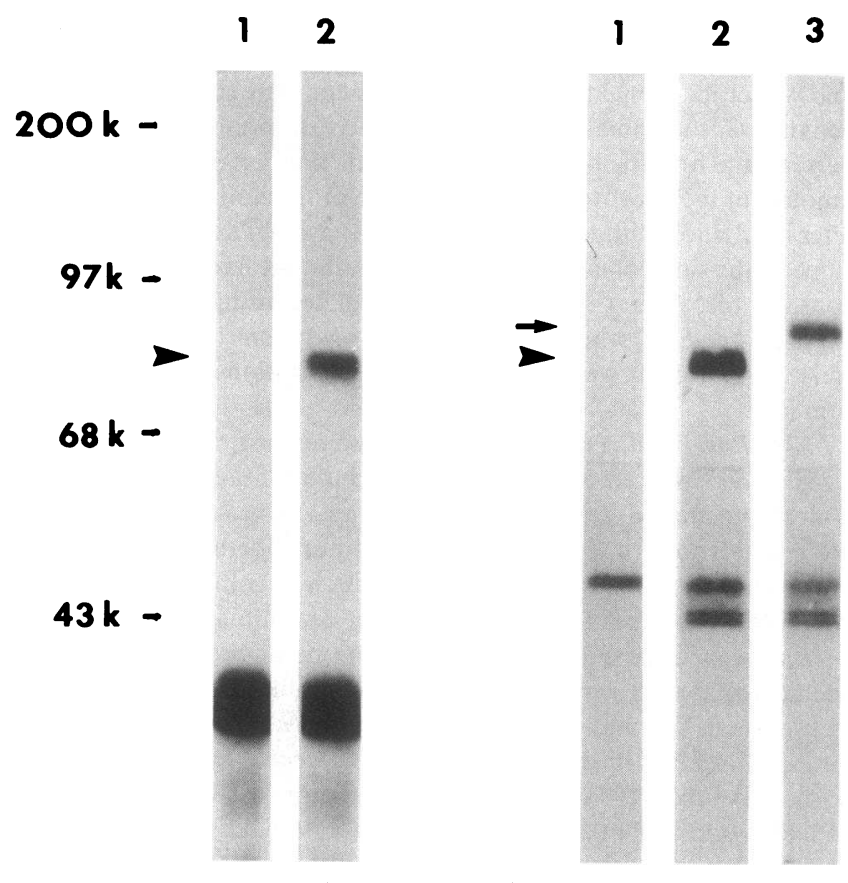

Figure 1. SDS-PAGE autoradiography showing complex formation between PA and a matrix-associated protein. $(A)$ Lane $l$ contains ${ }^{125} \mathrm{I}$-u-PA $(0.2 \mathrm{U})$ incubated with Tris-Tween buffer, whereas lane 2 shows ${ }^{125} \mathrm{I}$-u-PA after a 30 -min incubation with the matrix. The arrow $(\gg)$ indicates the complex formed between ${ }^{125} \mathrm{I}-\mathrm{u}-\mathrm{PA}$ and an unlabeled matrix protein. $(B)$ Matrices were metabolically labeled with $\left[{ }^{35} \mathrm{~S}\right]$ methionine and incubated for $30 \mathrm{~min}$ with buffer (lane 1 ), $0.5 \mathrm{U}$ unlabeled u-PA (lane 2) or $0.5 \mathrm{U}$ unlabeled t-PA (lane 3). In all cases matrix supernatants were analyzed. The arrows point to the complexes formed between u-PA $(>)$ or t-PA $(\rightarrow)$ and an ${ }^{35}$ S-labeled matrix protein.

sized by BSMCs, PAs were incubated with biosynthetically labeled BSMC matrices and the supernatants analyzed by SDS-PAGE (Fig. $1 B$ ). Supernatants from matrices incubated with Tris-Tween buffer contained a major band with an apparent molecular weight of $45 \mathrm{kD}$ (Fig. $1 \mathrm{~B}$, lane 1 ). In contrast when unlabeled u-PA was added to $\left[{ }^{35}\right.$ S $]$ methionine-labeled matrices three major bands were obtained; a 78-kD band that comigrated with the complex formed by ${ }^{125} \mathrm{I} \mathrm{u}-\mathrm{PA}$ and two bands at 45 and $41 \mathrm{kD}$. A similar pattern was also observed when proteins released from the matrix by t-PA were analyzed, but the t-PA matrix protein complex migrated with an apparent molecular weight of $83 \mathrm{kD}$ (Fig. $1 \mathrm{~B}$, lane 3). SDS-PAGE analysis of solubilized matrix proteins showed that a $45-\mathrm{kD}$ protein band was greatly diminished in intensity after treatment with u-PA (Fig. 2, arrow). The incorporation of $\left[{ }^{35} \mathrm{~S}\right]-$ methionine into matrix proteins depended on the labeling time and the cellular passage number. We therefore optimized the system to preferentially label the protein that complexed with u-PA. Matrix constituents that were released by t-PA or u-PA comprised as much as $10-15 \%$ of total counts incorporated into matrix protein. Furthermore, preincubation of matrices with t-PA abolished complex formation of subsequently added $\mathrm{u}-\mathrm{PA}$ and vice versa, indicating that $\mathrm{u}-\mathrm{PA}$ and t-PA form soluble complexes with the same matrix component.

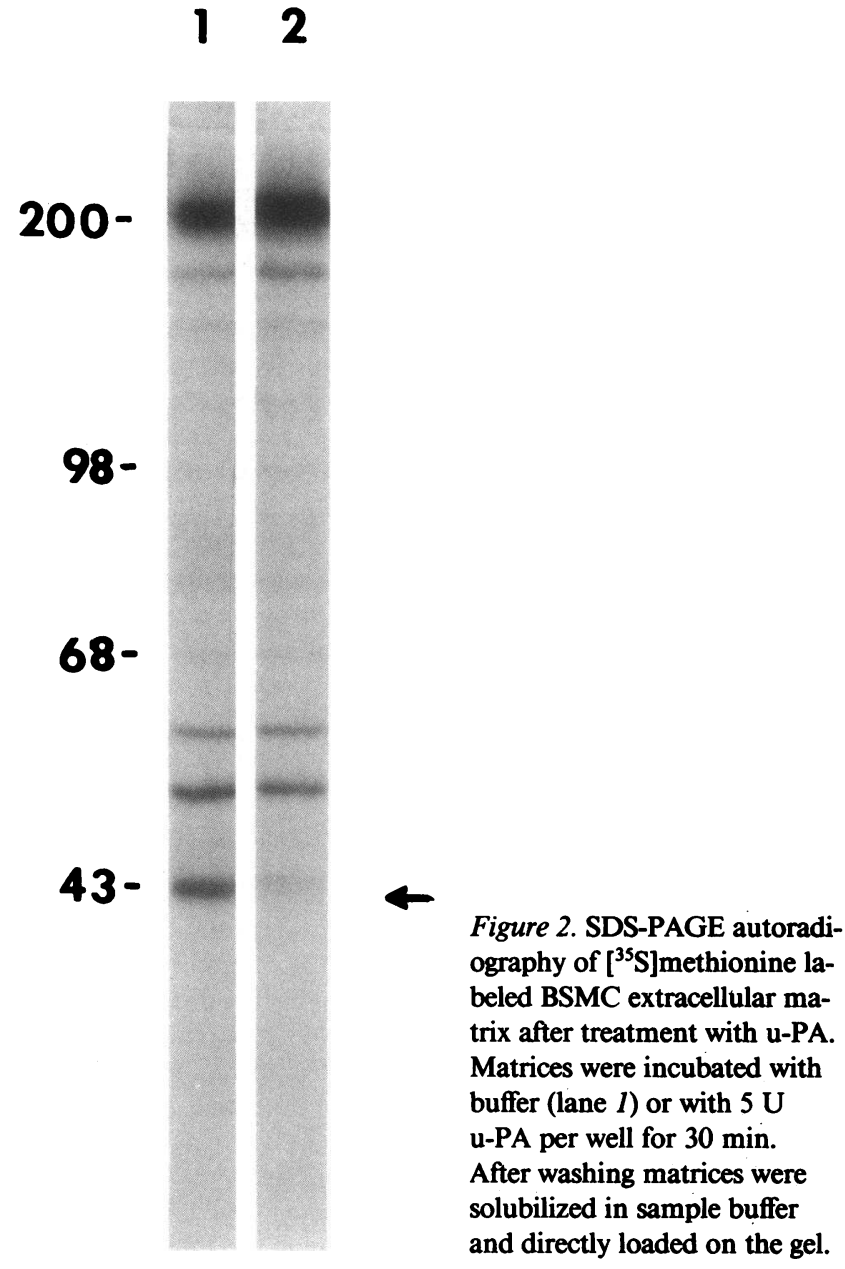

Diisopropyl fluorophosphate inactivated plasminogen activators did not show any complex formation.

Complex formation was accompanied by loss of u-PA enzymatic activity (Fig. 3). u-PA $(0.62 \mathrm{U})$ was incubated with matrices for increasing amounts of time and the u-PA-associated amidolytic activity in the supernatant was quantified fluorometrically at each timepoint. Maximal inhibition of u-PA occurred after $20 \mathrm{~min}$ while the amount of u-PA in the supernatant remained unchanged and no matrix bound u-PA was detectable by radiometric measurements. The overall rate constant for the bimolecular complex formation was $3.13 \pm 0.26 \times 10^{6} \mathrm{~s}^{-1} \mathrm{M}^{-1}$. As shown in Fig. 4 the amount of complex formed was proportional to the amount of u-PA added to $\left[{ }^{35} \mathrm{~S}\right]$ methionine-labeled matrices. Matrices produced by $5 \times 10^{4}$ BSMCs inhibited 1-1.5 U u-PA. With the dose-dependent increase in complex formation the bands at 41 and 45 $\mathrm{kD}$ also increased in intensity.

Characterization of the matrix associated $P A$ inhibitor. The specificity of the inhibitor for u-PA and t-PA was investigated by competitive inhibition studies. When ${ }^{125}$ I-u-PA was added to matrices with an equal amount of unlabeled u-PA or t-PA a 50\% reduction of complexes containing ${ }^{125}$ I u-PA was achieved (Fig. $5 \mathrm{~B}$ ). While an excess unlabeled u-PA or t-PA prevented complex formation of ${ }^{125}$ I u-PA with equal efficiency, an 80-fold molar excess of thrombin (1.6 U/well) did not diminish complex formation. The small amount of 


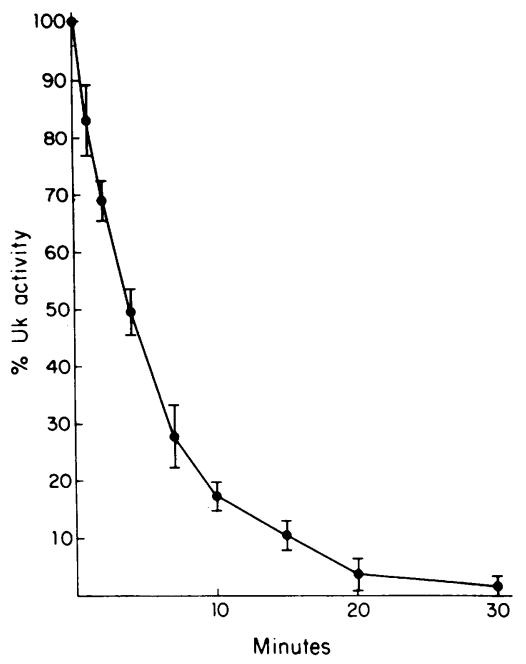

experiments with the standard error of the mean indicated by the bar.

thrombin used did not inactivate the matrix bound inhibitor during the 30-min incubation although higher thrombin concentrations (10 U/well) caused a decrease in ${ }^{125} \mathrm{I}$ u-PA complexes formed. Furthermore, ${ }^{125} \mathrm{I}$-thrombin (0.1-10 U) did not complex with any matrix component in the presence or absence of heparin, nor was the amidolytic activity of thrombin inhibited upon incubation with the matrix (data not shown). In addition to its specific affinity for u-PA and t-PA, the matrix-associated inhibitor was also stable under acidic conditions. All inhibitory activity was released from the matrix during a 1-h treatment at pH 2.7 (Table I) and was detectable in supernatants from acid-treated matrices.

SDS-PAGE analysis of biosynthetically labeled acid extracted proteins showed an intense band at $45 \mathrm{kD}$ and a second $56-\mathrm{kD}$ band. In addition two bands of 45 and $56 \mathrm{kD}$ were

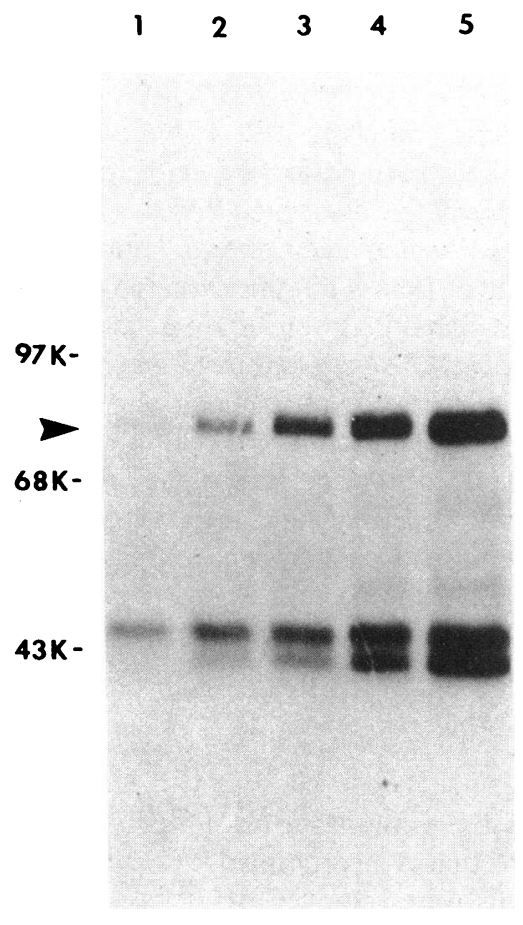

Figure 4. Dependence of U-PA-PA inhibitor complex formation on the concentration of u-PA added to matrix. ${ }^{35}$ S-labeled matrices were incubated for 30 min with increasing amounts of $\mathrm{u}-\mathrm{PA} ; \mathbf{( 0 . 0 8}$ $\mathrm{U}$, lane $1 ; 0.16 \mathrm{U}$, lane 2; $0.31 \mathrm{U}$, lane $3 ; 0.64$ $\mathrm{U}$, lane $4 ; 1.28 \mathrm{U}$ u-PA, lane 5). The supernatants containing ${ }^{35} \mathrm{~S}$-labeled u-PA-PA inhibitor complexes $(>)$ were then analyzed by SDSPAGE and autoradiography.
A

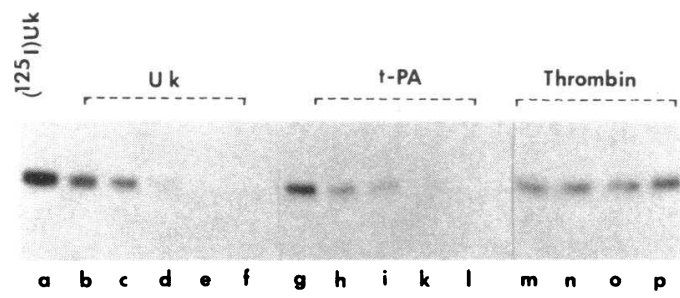

B

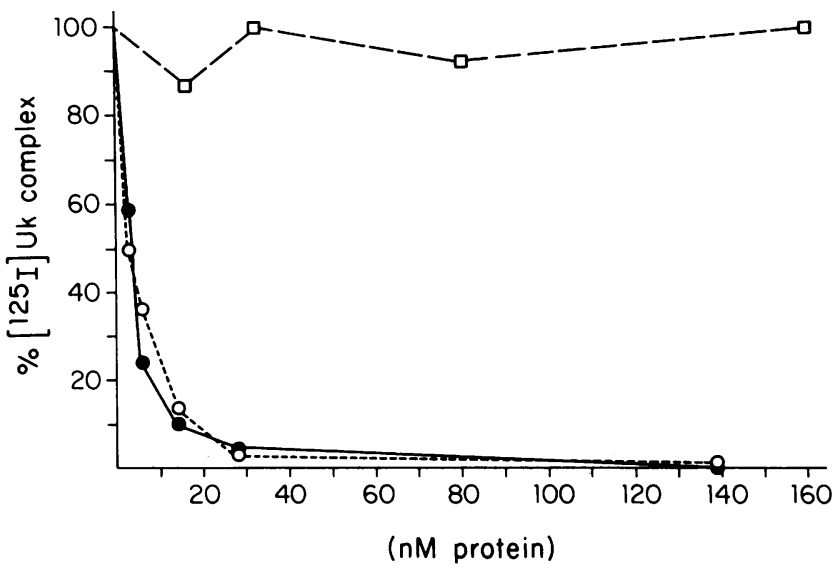

Figure 5. Specificity of complex formation between PAs and matrixassociated PA inhibitor. $(A)$ Autoradiograph of complexes formed after a 30-min incubation of $1.6 \mathrm{U}^{125} \mathrm{I}$-u-PA with the matrix in the presence of unlabeled u-PA, t-PA, or thrombin. Lane $a$ shows the amount of complex generated in the absence of any unlabeled competitor. Lanes $b-f$ and $g-l$ represent complex formation after addition of unlabeled u-PA or t-PA to $2.7 \mathrm{nM}^{125} \mathrm{I}-\mathrm{u}-\mathrm{PA}$ at a concentration of $2.7 \mathrm{nM}$ (lanes $b$ and $g$ ), $5.4 \mathrm{nM}$ (lanes $c$ and $h$ ), $13.8 \mathrm{nM}$ (lanes $d$ and $i$ ), $27.9 \mathrm{nM}$ (lanes $e$ and $k$ ) and $139 \mathrm{nM}$ (lanes $f$ and $l$ ). Lanes $m-p$ show the addition of ${ }^{125}$ I u-PA to the matrix together with thrombin at a concentration of $16 \mathrm{nM}$ (lane $m$ ), $32 \mathrm{nM}$ (lane $n$ ), $80 \mathrm{nM}$ (lane $o$ ) and $160 \mathrm{nM}$ (lane $p$ ). (B) Scan of the autoradiograph shown in $(A)$ to determine the relative amount ${ }^{125} \mathrm{I}-\mathrm{u}-\mathrm{PA}$ in complexes formed in the presence of the competitors u-PA (-O-), t-PA $(-\bullet-)$, and thrombin (-ロ-).

greatly diminished when the residual matrix proteins were solubilized and analyzed by SDS-PAGE and autoradiography (data not shown). As shown in Fig. $6 A$ (lanes 1-3) the lower 45-kD band was specifically recognized by the PAI- 1 antiserum (lane 2), but not by preimmune rabbit Ig (lane 3 ). In addition the immobilized PA inhibitor antibodies removed all functional u-PA inhibitory activity from the matrix acid supernatant (Fig. $6 \mathrm{~B}$ ) so that the presence of a second acid stable u-PA inhibitor species can be excluded. Thrombin also removed all inhibitory activity from the matrix. When crude supernatants from thrombin-treated matrices where analyzed by SDS-PAGE, they contained a $200-\mathrm{kD}$ band and a $41-\mathrm{kD}$ band (Fig. $6 A$, lane 4 ). The lower molecular weight species specifically reacted with the PAI-1 antiserum. Similarly when acid extracted $45-\mathrm{kD}$ inhibitor was incubated with thrombin (10 U), a 41-kD proteolytic fragment was generated.

Intact and modified PAI-1. To compare the functional properties of the intact acid extracted $45-\mathrm{kD}$ PAI-1 and the cleaved 41-kD PAI-1, both PAI-1 species were analyzed by SDS-PAGE after incubation with u-PA or t-PA and by reverse 
Table I. Removal of Matrix-associated u-PA Inhibitory Activity

\begin{tabular}{ll}
\hline Matrix treatment & $\begin{array}{l}\text { \% u-PA } \\
\text { inhibition }\end{array}$ \\
\hline TBS & $85.7 \pm 6.8$ \\
TBS/0.5\% tween & $86.1 \pm 3.8$ \\
$25 \mathrm{mM} \mathrm{EDTA}$ & $95.0 \pm 4.1$ \\
$2 \mathrm{M} \mathrm{NaCl}$ & $92.0 \pm 4.8$ \\
$100 \mathrm{U} / \mathrm{ml}$ heparin & $90.8 \pm 4.8$ \\
& \\
$0.1 \% \mathrm{SDS}$ & $4.3 \pm 4.2$ \\
$5 \mathrm{M} \mathrm{urea}$ & $5.0 \pm 3.8$ \\
$5 \mathrm{M} \mathrm{GuCl} \mathrm{pH} 7.0$ & $5.8 \pm 5.5$ \\
Glycine/HCl pH 2.7 & $7.3 \pm 6.2$ \\
\hline
\end{tabular}

BSMC matrices were treated for $1 \mathrm{~h}$ at $25^{\circ} \mathrm{C}$ as indicated, washed and the remaining matrix-associated PA inhibitor quantified by the addition of $1.5 \mathrm{U}$ u-PA for $30 \mathrm{~min}$. u-PA activity in the supernatant was measured by the fluorometric assay and the percent inhibition expressed relative to the activity of $1.5 \mathrm{U}$ free u-PA. Values represent the mean of six individual experiments with the standard error of the mean.

zymography. As shown in Fig. $7 A$ (lanes 2 and 3), the acid extracted PAI-1 formed high molecular weight complexes with both $\mathrm{u}-\mathrm{PA}$ and t-PA and was also functionally active when subjected to reverse zymography (Fig. $7 \mathrm{~B}$, lane 1 ). On the other hand PAI-1 released from the matrix by thrombin neither formed high molecular weight complexes (Fig. $7 \mathrm{~A}$, lanes 5 and 6) nor prevented the lysis of the casein in the underlying indicator gel (Fig. $7 \mathrm{~B}$, lane 2). u-PA and t-PA also cleaved the 56-kD protein but since this protein was neither recognized by the PA inhibitor antiserum nor showed activity on the zymograms, it was not further characterized. It is interesting that incubation of matrices or matrix acid extracts with u-PA and t-PA also resulted in the generation of the two forms of PA inhibitor. The upper band comigrated with PA inhibitor obtained from acid extracts, whereas the lower band showed the same mobility as the thrombin-treated PA inhibitor. Both forms specifically reacted with the PA inhibitor antiserum (Fig. 8, lane 4). To investigate the origin of the 45- and 41-kD PA inhibitors, u-PA-PA inhibitor complexes were isolated. Only minimal dissociation of the purified protease-inhibitor complex during the electrophoretic analysis was noticed (Fig. 8 , lane 2), suggesting that the two uncomplexed PA inhibitor species were not generated by dissociation of unstable u-PAPA inhibitor complexes upon SDS-PAGE. However, when the isolated u-PA- $\left[{ }^{35} \mathrm{~S}\right] \mathrm{PA}$ inhibitor complexes were incubated

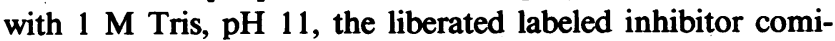
grated with the 41-kD inhibitor species on SDS-PAGE (Fig. 8, lane 3). u-PA must therefore have cleaved the inhibitor during the generation of the covalent u-PA-inhibitor bond.

To further characterize the interaction of PAI-1 with the matrix the effects $0.05 \%$ Tween, high salt $(2 \mathrm{M} \mathrm{NaCl})$, heparin (100 U/well) or EDTA $(25 \mathrm{mM})$ on the release of matrix bound PA inhibitor were tested (Table I). None of these agents removed significant amounts of inhibitor. In contrast harsher reagents such as urea $(5 \mathrm{M})$, guanidinium chloride $(4 \mathrm{M}), 0.1 \%$ SDS or glycine- $\mathrm{HCl}$ ( $\mathrm{pH} 2.7$ ) completely removed PAI-1 from the matrix.
A

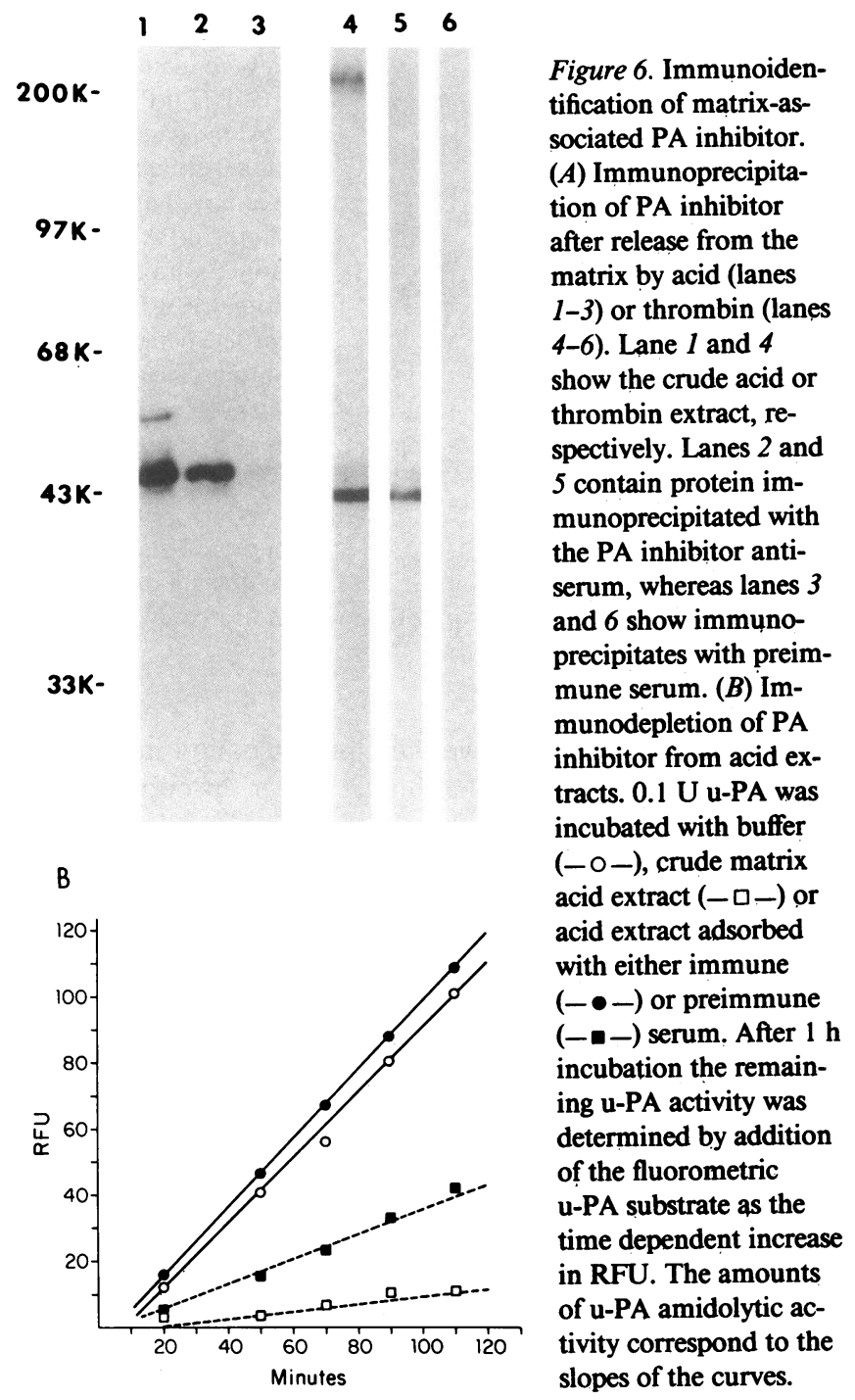

Interaction of normal and malignant cells with matrix associated PAI-1. Since PAs have been implicated in the invasive behavior of various tumors, matrix-associated PAI might provide a major obstacle to the PA-mediated tumor cell migration and metastasis. The effects of Bowes human melanoma cells and BSMCs on matrix-associated PAI were compared. After a 4-h culture on the matrix the cells were removed and matrix acid extracts analyzed by SDS-PAGE autoradiography (Fig. 9 $A$ ), zymography (Fig. $9 B$ ) and by immunoprecipitation (Fig. 9 $C)$. Whereas acid extracts from matrices exposed to BSMCs contained a 45-kD band with functional and antigenic properties of PAI-1, such a protein was lacking in acid extracts from matrices exposed to Bowes melanoma cells. A higher molecular weight protein (Fig. $9 \mathrm{~A}$ ) as well as other matrix proteins (data not shown) were not significantly affected.

\section{Discussion}

We have shown that BSMCs synthesize a functionally active PAI of both u-PA and t-PA that is incorporated into the extracellular matrix. When cells were removed under conditions 
A

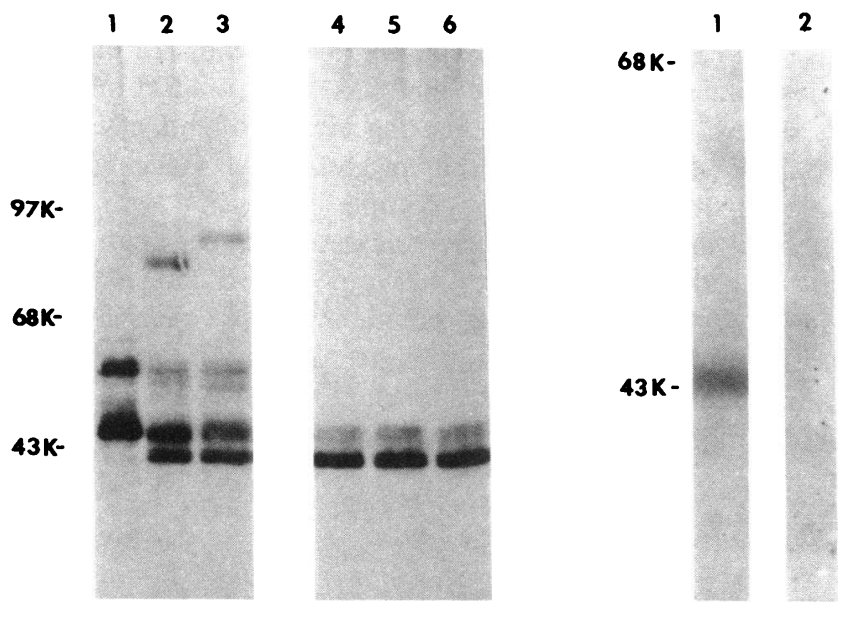

Figure 7. SDS-PAGE autoradiography showing complex formation between PA and PA inhibitor in the fluid phase. $(A)$ Proteins were released from ${ }^{35} \mathrm{~S}$-labeled matrices by acid treatment (lanes $1-3$ ) or enzymatically by thrombin ( $10 \mathrm{U} /$ well; lanes 4-6). The supernatants were then incubated with buffer (lanes 1 and 4), $5 \mathrm{U}$ u-PA (lane 2 and 5) or $5 \mathrm{U}$ t-PA (lane 3 and 6 ). The thrombin was completely inhibited by PPACK before addition of PAs. (B) Reverse zymography of acid extract (lane 1 ) and thrombin extract (lane 2).

that did not involve cell lysis (with EDTA or collagenase, data not shown) instead of the routinely used $0.5 \%$ Triton X-100, $25 \mathrm{mM} \mathrm{NH}_{4} \mathrm{OH}$ treatment, similar results were obtained. Therefore PAI was not adsorbed onto the matrix after cell lysis. The interaction of PAs with the matrix resulted in rapid and complete enzyme inhibition and the appearance of bimolecular PA-PAI complexes in the supernatant (Fig. 1). Complexes with identical electrophoretic mobility were also observed when t-PA and u-PA were incubated with matrices from human and bovine endothelial cells and human foreskin or lung fibroblasts thereby demonstrating the ubiquitous nature of this matrix constituent (data not shown). The specific reactivity of the matrix associated PAI for t-PA and $\mathrm{u}-\mathrm{PA}$, the

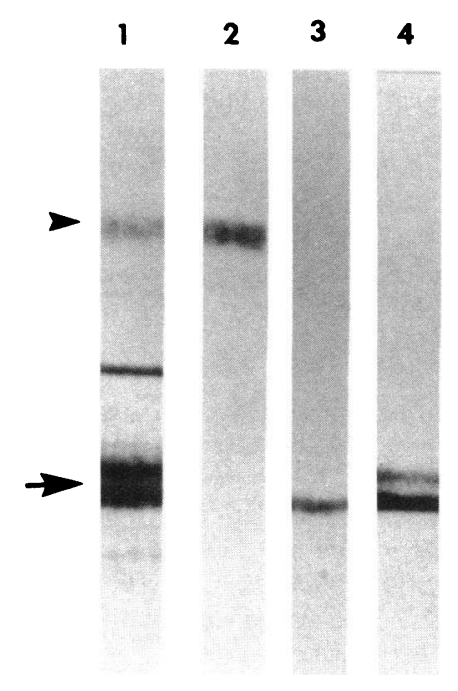

Figure 8. Dissociation of u-PA-PA inhibitor complexes. Supernatants from $\left[{ }^{35} \mathrm{~S}\right]$ methionine labeled, u-PA treated matrices (lane 1 ) were incubated with immobilized anti-u-PA antibodies and the isolated u-PA-PA inhibitor complexes $(>)$ (lane 2) analyzed by SDS-PAGE and autoradiography. Lane 3 shows the dissociated $\left[{ }^{35} \mathrm{~S}\right] \mathrm{PA}$ inhibitor after incubation of the isolated u-PA-PA inhibitor complex with $1 \mathrm{M}$ Tris, $\mathrm{pH}$ 11. Lane 4 contains uncomplexed PA inhibitor $(\rightarrow$ ) immunoprecipitated with an immobilized PA inhibitor antiserum.
A

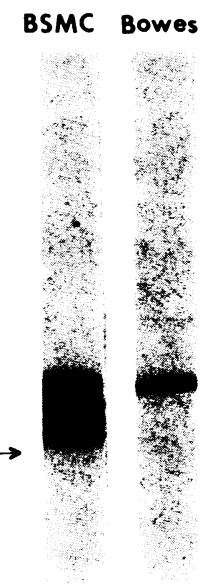

B

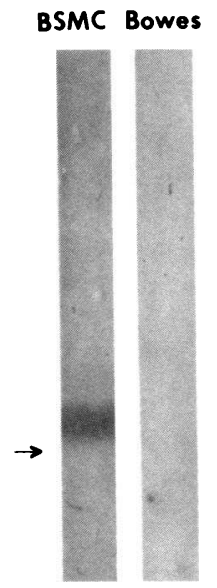

C

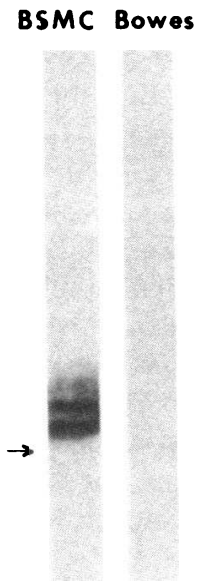

Figure 9. Removal of PA inhibitor from the matrix by Bowes melanoma cells. BSMCs or Bowes melanoma cells were seeded on $\left[{ }^{35} \mathrm{~S}\right]-$ methionine-labeled BSMC matrices. After $4 \mathrm{~h}$ adherent cells were removed and acid extracted proteins were compared by SDS-PAGE and autoradiography $(A)$ or reverse zymography $(B) .(C)$ shows an immunoprecipitation with immobilized PA inhibitor antibodies of acid extracted proteins from BSMC or Bowes exposed matrices. Parallel immunoprecipitations with preimmune serum did not show any bands on autoradiography. The arrow indicates $43 \mathrm{kD}$.

fast rate of association with both u-PA and t-PA and the acid stability strongly suggested that the inhibitor was not of the protease nexin type. We were not able to detect protease nexin in the BSMC extracellular matrix by reactivity with a thrombin probe even though the extracellular matrix enhances the activity of this inhibitor (39).

Two antigenically distinct PAIs have been reported, an endothelial PAI (PAI-1) $(35,40)$ and a placental (41) PAI (PAI-2), that are best distinguished by monospecific, noncross-reactive antisera. Reactivity of the PA inhibitor in BSMC matrix with a well characterized antiserum raised against the PAI-1 (35) identified the BSMC inhibitor as of endothelial type (Fig. 6). Furthermore no functional PAI was detectable in acid extracts from BSMC matrices after immunodepletion with the anti-PAI-1 antiserum suggesting the absence of a PAI-2 from BSMC extracellular matrix. PAI-1, the major form of circulating PA inhibitor (40) has previously been implicated in the intravascular control of t-PA activity during fibrinolysis (42). The molecular weight of the matrix associated PAI-1 was $45 \mathrm{kD}$, whereas other published reports range from 47.5 to 54 $\mathrm{kD}$. The reason for this difference remains to be determined. The presence of PAI-1 in the extracellular matrix of cells in the vessel wall extends the biological role of PAI-1 to the control of PA-mediated events in the extravascular space.

The complex formed between u-PA and the matrix-associated PAI- 1 was resistant to treatment with SDS and $\beta$-mercaptoethanol. The PAI-1-PA complex demonstrated unusual stability on SDS-PAGE since dissociation did not occur during electrophoresis in the Laemmli gel system but required prolonged incubation in $1 \mathrm{M}$ Tris at $\mathrm{pH} 11$. Therefore, the mechanism involved in complex formation of serine proteinase inhibitors with their corresponding proteinases (43) most likely also applies to the complex formed between PAI and u-PA or 
t-PA. The formation of the enzyme inhibitor complex was accompanied by the loss of a 4-5-kD polypeptide so that PAI-1 recovered from the U-PA-PAI-1 complex consisted entirely of the 41-kD modified PAI-1 species and not the 45-kD intact PAI-1 (Fig. 8). In addition to the active 45-kD PAI-1 species that rapidly complexed with u-PA, substantial amounts of an uncomplexed 45-kD PAI-1 were detectable on SDS-PAGE (Fig. 7). The reason for the presence of this inactive molecular species remains to be determined. Nevertheless, the inactive $45-\mathrm{kD}$ species remained a good substrate for $\mathrm{u}-\mathrm{PA}$ since it was cleaved by u-PA in a dose dependent fashion into the 41-kD PAI-1 (Fig. 4) (44). In addition to u-PA and t-PA high concentrations (10 U) of thrombin (Fig. 6) or plasmin (data not shown) also cleaved PAI-1 into the 41-kD functionally inactive species without the formation of SDS stable complexes.

Dissociation of PAI-1 from the matrix occurred either during acid treatment that released the intact $45-\mathrm{kD}$ species or by the loss of the 4-5-kD polypeptide during the incubation with u-PA, t-PA, or thrombin. Since cleavage of PAI-1 was not required for its release from the matrix, the disruption of the matrix-PAI-1 bond appears to be mediated through a conformational change in the inhibitor. Furthermore the association of PAI-1 with the matrix could not be disrupted by incubation with $2 \mathrm{M} \mathrm{NaCl}$, EDTA or heparin (Table I) suggesting that the binding was not simply ionic or divalent cation dependent. After its dissociation from the matrix the 45-kD PAI-1 quickly lost up to $90 \%$ of its activity upon storage at $4^{\circ} \mathrm{C}$ or freezethawing (data not shown). Therefore the association with the extracellular matrix appears to stabilize the functional activity of PAI-1.

Plasminogen activators have been implicated in the invasive behavior of certain tumor cells. Quigley first demonstrated that PMA-treated Rous sarcoma virus transformed chick embryo fibroblasts when cultured on extracellular matrices undergo a PA-mediated morphological change in the complete absence of plasminogen $(45,46)$. Addition of low molecular weight inhibitors of PAs as well as a specific monoclonal antibody that blocked functional PA activity prevented cluster formation of Rous sarcoma virus transformed chick embryo fibroblasts. These experiments strongly suggest that PA has a direct effect on cell matrix interactions. The increased secretion of PAs as a result of cellular transformation facilitates matrix destruction by some tumor cells during their migration through the vessel wall (47) and the establishment of metastasis (48). Ossowski and Reich (49) first showed that antibodies to $\mathrm{u}-\mathrm{PA}$ considerably diminished the generation of lung metastasis by HEp2 human carcinoma cells seeded onto the chick chorioallantoic membrane, suggesting that u-PA was involved at a crucial step during the formation of metastasis. Furthermore a rat smooth muscle cell extracellular matrix was used to demonstrate inhibition of invasion and cell proliferation by protease nexin of the u-PA producing fibrosarcoma cell line, HT 1080 (50). Since protease nexin blocks both u-PA and plasmin activity, the exact mechanism of tumor cell invasion in this system remains unknown.

The PA-mediated degradation of chick embryo fibroblast extracellular matrices was characterized by an initial lag period (51), suggesting that matrix-associated PA inhibitor initially neutralized tumor cell PA. In the present study, matrix acid extracts contained no PAI-1 after exposure of matrices to t-PA producing Bowes melanoma cells (Fig. 9). In addition a strain of HT 1080 cells that elaborates copious amounts of u-PA also caused a loss of acid extracted matrix associated PAI-1 (data not shown). On the other hand BSMCs, fibroblasts, and an other human melanoma cell line, C32, did not affect matrixassociated PAI-1. The apparent specificity of this effect by certain PA-secreting tumor cells suggests that PAI-1 might be removed from the matrix by complex formation with PAs. Alternatively, PAI- 1 could be released from the matrix or cross-linked to the matrix by other tumor-associated enzymes. Since the role of PA in matrix remodeling and degradation has clearly been established, the presence of a matrix-associated PA inhibitor may provide an important regulatory component for a number of physiological and pathological processes.

\section{Acknowledgments}

This work was supported by the National Heart, Lung, and Blood Institute grant HL-18828 (Specialized Center of Research in Thrombosis) and grant HL-30649 from the National Institutes of Health. Additional support was provided by the Krakower Foundation.

\section{References}

1. Loskutoff, D., and T. S. Edington. 1977. Synthesis of a fibrinolytic activator and inhibitor by endothelial cells. Proc. Natl. Acad. Sci. USA. 74:3903-3907.

2. Williams, J. R. B. 1951. Fibrinolytic activity of urine. Br. J. Exp. Pathol. 32:530-537.

3. Astrup, T. 1975. Cell induced fibrinolysis: a fundamental process. In Proteases and Biological Control. E. Reich, D. B. Rifkin, and E. Shaw, editors. Cold Spring Harbor Laboratory, New York. 343-355.

4. Ossowski. L., J. P. Quigley, and E. Reich. 1975. Plasminogen, a necessary factor for cell migration in-vitro. In Proteases and Biological Control. E. Reich, D. B. Rifkin, and E. Shaw, editors. Cold Spring Harbor Laboratory, New York. 901-913.

5. Alvarez-Buylla, A., and J. E. Valinsky. 1985. Production of plasminogen activator in cultures of superior cervical ganglia and isolated schwann cells. Proc. Natl. Acad. Sci. USA. 82:3519-3523.

6. Strickland, S., and W. H. Beers. 1976. Studies on the role of plasminogen activator in ovulation: in vitro response of granulosa cells to gonadatropins, cyclic nucleotides and prostaglandins. J. Biol. Chem. 251:5694-5702.

7. Werb, Z., C. L. Mainardi, C. A. Vater, and E. D. Harris Jr. 1977. Endogenous activation of latent collagenase by rheumatoid synovial cells. Evidence for a role of plasminogen activator. N. Engl. J. Med. 296:1017-1023.

8. Markus, G. 1984. The role of hemostasis and fibrinolysis in the metastatic spread of cancer. Semin. Thromb. Hemostasis. 10:61-70.

9. Bachman, F., and E. K. O. Kruithof. 1984. Tissue plasminogen activator: chemical and physiological aspects. Semin. Thromb. Hemostasis. 10:6-17.

10. Gelehrter, T. D., and R. Sznycer-Laszuk. 1986. Thrombin induction of plasminogen activator-inhibitor in cultured human endothelial cells. J. Clin. Invest. 77:165-169.

11. Colucci, M., J. A. Paramo, and D. Collen. 1985. Generation in plasma of a fast-acting inhibitor of plasminogen activator in response to endotoxin stimulation. J. Clin. Invest. 75:818-824.

12. Nachman, R. L., K. A. Hajjar, R. L. Silverstein, and C. A. Dinarello. 1986. Interleukin 1 induces endothelial cell synthesis of plasminogen activator inhibitor. J. Exp. Med. 163:1595-1600.

13. Emeis, J. J., and T. Kooistra. 1986. Interleukin 1 and lipopolysaccharide induce an inhibitor of tissue-type plasminogen activator in vivo and in cultured cells. J. Exp. Med. 163:1260-1266.

14. Bevilacqua, M. P., R. R. Scleef, M. A. Gimbrone, and D. J. 
Loskutoff. 1986. Regulation of the fibrinolytic system of cultured human vascular endothelium by interleukin 1. J. Clin. Invest. 78:587591.

15. Rifkin, D. B. 1978. Plasminogen activator synthesis by cultured human embryonic lung cells: characterization of the suppressive effect of corticosteroids. J. Cell. Physiol. 97:421-428.

16. Coleman, P. L., P. A. Barouski, and T. D. Gelehrter. 1982. The dexamethasone-induced inhibitor of fibrinolytic activity in hepatoma cells. J. Biol. Chem. 257:4260-4264.

17. Dosne, A. M., E. Dupuy, and E. Bodevin. 1978. Production of a fibrinolytic inhibitor by cultured endothelial cells derived from human umbilical vein. Thromb. Res. 12:377-387.

18. Loskutoff, D. J., and T. S. Edington. 1981. An inhibitor of plasminogen activator in rabbit endothelial cells. J. Biol. Chem. 256:4142-4145.

19. Loskutoff, D. J., J. A. van Mourik, L. A. Erickson, and D. Lawrence. 1983. Detection of an unusually stable fibrinolytic inhibitor produced by bovine endothelial cells. Proc. Natl. Acad. Sci. USA. 80:2956-2960.

20. Levin, E. G. 1983. Latent tissue plasminogen activator produced by human endothelial cells in culture. Evidence for an enzymeinhibitor complex. Proc. Natl. Acad. Sci. USA. 80:6804-6808.

21. Kawano, T., K. Morimoto, and Y. Uemura. 1970. Partail purification and properties of urokinase inhibitor from human placenta. $J$. Biochem. 67:333-342.

22. Baker, B. J., D. A. Low, R. L. Simmer, and D. D. Cunningham. 1980. Protease-nexin: a cellular component that links thrombin and plasminogen activator and mediates their binding to cells. Cell. $21: 37-45$.

23. Stump, D. C., M. Thienpont, and D. Collen. 1986. Purification and characterization of a novel inhibitor of urokinase from human urine. J. Biol. Chem. 261:12759-12766.

24. Kruithof, E. K. O., C. Tran-Thang, and F. Bachman. 1986. The fast acting inhibitor of tissue-type plasminogen activator in plasma is also the primary plasma inhibitor of urokinase. Thromb. Haemostasis. 55:65-69.

25. Holmberg, L., I. Lecander, B. Person, and B. Astedt. 1978. An inhibitor from placenta specifically binds urokinase and inhibits plasminogen activator released from ovarian carcinoma in tissue culture. Biochim. Biophys. Acta. 544:128-137.

26. Kruithof, E. K. O., C. Tran-Thang, A. Ransijn, and F. Bachman. 1984. Demonstration of a fast acting inhibitor of plasminogen activators in human plasma. Blood. 64:907-913.

27. Kruithof, E. K. O., J.-D. Vassalli, W.-D. Schleuning, R. J. Mattaliano, and F. Bachman. 1986. Purification and characterisation of a plasminogen activator inhibitor from the histiocytic lymphoma cell line U-937. J. Biol. Chem. 261:11207-1121327.

28. Low, D. A., J. B. Baker, W. C. Koonce, and D. D. Cunningham. 1981. Released protease-nexin regulates cellular binding, internalisation and degradation of serine proteases. Proc. Natl. Acad. Sci. USA. 78:2340-2344. 223s.

29. Hay, E. D. 1981. Extracellular matrix. J. Cell Biol. 91:205s-

30. Jones, P. A., and Y. De Cleck. 1980. Destruction of extracellular matrices containing glycoproteins, elastin and collagen by metastatic human tumor cells. Cancer Res. 40:3222-3227.

31. Murphy, G., J. J. Reynold, and Z. Werb. 1985. Biosynthesis of tissue inhibitor of metalloproteinases by human fibroblasts in culture. J. Biol. Chem. 260:3079-3083.

32. Sheela, S., and J. C. Barrett. 1982. In vitro degradation of radiolabeled, intact basement membrane mediated by cellular plasminogen activator. Carcinogenesis. 3:363-369.
33. Keski-Oja, J., and A. Vaheri. 1982. The cellular target for the plasminogen activator, urokinase, in human fibroblasts $-66,000$ dalton protein. Biochim. Biophys. Acta. 720:141-146.

34. Knudsen, B. S., R. L. Silverstein, L. L. K. Leung, P. C. Harpel, and R. L. Nachman. 1986. Binding of plasminogen to extracellular matrix. J. Biol. Chem. 261:10765-10771.

35. van Mourik, J. A., D. A. Lawrence, and D. J. Loskutoff. 1984. Purification of an inhibitor of plasminogen activator (antiactivator) synthesized by endothelial cells. J. Biol. Chem. 259:14914-14921.

36. Gospodarowicz, D., D. Delago, and I. Vlodavsky. 1980. Permissive effect of the extracellular matrix on cell proliferation in vitro. Proc. Natl. Acad. Sci. USA. 77:4094-4098.

37. Silverstein, R. L., R. L. Nachman, L. L. K. Leung, and P. C. Harpel. 1985. Activation of immobilized plasminogen by tissue activator. J. Biol. Chem. 260:10346-10352.

38. Christensen, U., L. Holmberg, B. Bladh, and B. Astedt. 1982. Kinetics of the reaction between urokinase and an inhibitor of fibrinolysis from placental tissue. Thromb. Haemostasis. 48:24-26.

39. Farrell, D. H., and D. D. Cunningham. 1986. Human fibroblasts accelerate the inhibition of thrombin by protease nexin. Proc. Natl. Acad. Sci. USA. 83:6858-6862.

40. Erickson, L. A., C. M. Hekman, and D. J. Loskutoff. 1985. The primary plasminogen activator inhibitors in endothelial cells, platelets, serum and plasma are immunologically related. Proc. Natl. Acad. Sci. USA. 82:8710-8714.

41. Astedt, B., I. Lecander, T. Brodin, A. Lundbald, and K. Loew. 1985. Purification of a specific placental plasminogen activator inhibitor by monoclonal antibody and its complex formation with plasminogen activator. Thromb. Haemostasis. 53:122-125.

42. Colucci, M., J. A. Paramo, J. M. Stassen, and D. Collen. 1986. Influence of the fast acting inhibitor of plasminogen activator on in vivo thrombolysis induced by tissue type plasminogen activator in rabbits. J. Clin. Invest. 78:138-144.

43. Travis, J., and G. S. Salvesen. 1983. Human plasma proteinase inhibitors. Annu. Rev. Biochem. 52:655-709.

44. Nielsen, L. S., P. A. Andreasen, J. Grondahl-Hansen, L. Skriver, and K. Dano. 1986. Plasminogen activators catalyse conversion of inhibitor from fibrosarcoma cells to an inactive form with a lower apparent molecular mass. FEBS (Fed. Eur. Biochem. Soc.) Lett. 196:269-273.

45. Quigley, J. P. 1979. Phorbol ester-induced morphological changes in transformed chick fibroblasts. Evidence for direct catalytic involvement of plasminogen activator. Cell. 17:131-141.

46. Sullivan, L. M., and J. P. Quigley. 1986. An anticatalytic monoclonal antibody to avian plasminogen activator. Its effect on behavior of RSV-transformed chick fibroblasts. Cell. 45:905-915.

47. Mullins, D. E., and S. T. Rohrlich. 1983. The role of proteinasis in cellular invasiveness. Biochim. Biophys. Acta. 695:177-214.

48. Saito, D., M. Sawamura, K. Umezawa, Y. Kanai, C. Furihata, T. Matsushima, and T. Sugimura. 1980. Inhibition of blood-borne lung metastasis by protease inhibitors. Cancer Res. 40:2539-2542.

49. Ossowski, L., and E. Reich. 1983. Antibodies to plasminogen activator inhibit tumor metastasis. Cell. 35:611-619.

50. Bergman, B. L., R. W. Scott, A. Bajpai, S. Watts. and J. B. Baker. 1986. Inhibition of tumor-cell-mediated extracellular matrix destruction by a fibroblast proteinase inhibitor, Protease nexin I. Proc. Natl. Acad. Sci. USA. 83:996-1000.

51. Fairbairn, S., R. Gilbert, G. Ojakaian, R. Schwimmer, and J. P. Quigley. 1985. The extracellular matrix of normal chick embryo fibroblasts. Its effect on transformed chick fibroblasts and its proteolytic degradation by the transformants. J. Cell Biol. 101:1790-1798. 